\title{
Produção artesanal com fibras naturais e abordagem social: perspectivas sustentáveis.
}

Artisanal production with natural fibers and social approach: sustainable perspectives.

SETTE, Soleni dos Santos Kuhn; Mestranda em Design; Univille

solkuhn@hotmail.com

MORGENSTERN, Elenir; Doutora em Design; Univille

elenir.m@gmail.com

\section{Resumo}

O artigo aborda a construção de artefatos e o reconhecimento do trabalho artesão que contribui com bem estar socioambiental e exemplifica a demanda de exportação desses produtos. Em seu desenvolvimento adentra em questões relacionadas sustentabilidade, abordagem social e mercado. $\mathrm{O}$ artigo argumenta sobre a relevância da consideração ao meio ambiente no desenvolvimento de fio têxtil, a partir da integração entre fibras naturais: fibras de paina e fibras de bananeira. $\mathrm{O}$ apoio teorético para o desenvolvimento do artigo está na abordagem social do conhecimento. Neste viés o artigo desdobra-se considerando os agentes envolvidos no processo e valores simbólicos instituídos pelo mercado.

Palavras Chave: fibras naturais; sustentável; abordagem social.

\section{Abstract}

The article deals with the construction of artifacts and the recognition of artisan work that contributes to social and environmental well-being and exemplifies the export demand of these products. In its development it enters into issues related to sustainability, social approach and market. The article argues about the relevance of consideration to the environment in the development of textile yarn, from the integration between natural fibers: fibers of paina and banana fibers. The theoretical support for the development of the article is in the social approach to knowledge. In this bias the article unfolds considering the agents involved in the process and symbolic values established by the market.

Keywords: Natural fibers; Sustainable; Social approach. 


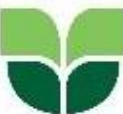 \\ univille}

\section{Introdução}

$\mathrm{O}$ artigo ${ }^{1}$ apresenta uma abordagem geral de como os trabalhos artesanais, especialmentes os que na sua construção utilizam de materiais naturais (fibras), podem contribuir com a sustentabilidade, com o meio social e ainda ser inseridos no mercado.

Reuniu-se informações, para apontar iniciativas sustentáveis de sucesso, as possibilidades de inserção no mercado internacional e avaliar o impacto social nesse contexto.

A relevância desta reflexão justifica-se pela mudança de hábitos de consumo. Nota-se um pensamento abrangente e humanitário. Nesse contexto percebe-se oportunidades de inserção no mercado de bens e serviços, disseminando a cultura de preservação ambiental e de sociedade com oportunidades justas.

Em seu desdobramento o artigo discorre acerca da sustentabilidade e uso de fibras naturais; abordagem social; consumidor movido por valores; e a valorização internacional dos produtos artesanais. Conclui argumentando acerca da relevância de produções que considerem o meio ambiente por meio de práticas artesanais utilizando-se recursos naturais renováveis.

\section{Sustentabilidade e uso de Fibras naturais}

A elaboração de um artefato, por meio de processos não agressivos de construção, utilizando-se materiais naturais e processos artesanais, pode configurar um produto sustentável. Conforme Cardoso (2008, p.3) "Todo produto, independente de seu material, provoca impactos ao meio ambiente, seja por meio da sua produção, pelas matérias primas utilizadas ou ainda durante seu uso ou descarte".

A ampliação de opções em matéria prima têxtil acrescenta de forma positiva ao campo do design de moda, pois ao levantarem-se alternativas de uso de fibra natural, no desenvolvimento de artefatos, estar-se-á valorizando, essencialmente, a característica sustentável. Cardoso (2008, p.2) aborda sobre o conceito do desenvolvimento sustentável "O conceito atualmente contempla temas globais como a degradação ambiental, mudança do clima e perda da biodiversidade e ainda az uma ligação entre essas questões de âmbito ecológico e outras de âmbito social e econômico“. Pode-se perceber, principalmente partindo da abordagem dos últimos dois aspectos (âmbito social e econômico), a relevância da investigação ora relatada.

O destaque da investigação encontra-se nos aspectos econômicos promovidos pela pesquisa, de modo particular, aborda o impacto social voltado ao uso de produtos ambientalmente amigáveis na construção de materiais e (ou) artefatos de diversas espécies bem como a valorização internacional que vem acontecendo de modo singelo porém crescente. Para Manzini (2008) para acontecer a "sustentabilidade ambiental" as atividades humanas não devem interferir nos ciclos naturais além dos limites de resiliência dos ecossistemas de base e também não devem empobrecer o capital natural das futuras gerações.

\footnotetext{
${ }^{1} \mathrm{O}$ presente artigo intitulado "Produção artesanal com fibras naturais e abordagem social: perspectivas sustentáveis", foi elaborado a partir do conhecimento construído na disciplina de Cenários no curso de Mestrado em Design.
} 


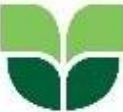 \\ univille}

Tem-se notado forte necessidade de construção de produtos por meio de métodos sustentáveis. Em consonância a essa demanda, a utilização de fibras naturais é vista, nesta proposição investigativa, como um passo em direção à sustentabilidade. $O$ termo 'Desenvolvimento sustentável' é muito amplo e procurando esclarecer, Naime et al. (2012 p. 1511) traz uma breve descrição: "Desenvolvimento sustentável pode ser definido de forma mais abrangente como a busca de equilíbrio entre tecnologia e ambiente, com participação de todos os grupos sociais e nações, em busca da qualidade de vida, equidade e justiça social."

Um Designer, por meio de suas criações, instiga o consumo, entende-se que essa provocação precisa levar em consideração à ética e a sociedade e considerar as pessoas como agentes, imprimindo no produto criado a mensagem do pensar no coletivo, no bem estar social e no meio ambiente.

A sustentabilidade pode ser definida em três dimensões: ambiental, econômica e social. Logo que falamos em pensar sustentabilidade o direcionamento mais comum é para o pensamento ambiental, amplamente estudado em função da degradação; poluição; espécies extintas; escassez de matéria prima etc. Prega-se que o ideal é não produzir em excesso. Nascimento (2012, p.55) aborda a $1^{\text {a }}$ dimensão da sustentabilidade, a ambiental, escreve que "Trata-se, portanto, de produzir e consumir de forma a garantir que os ecossistemas possam manter sua autorreparação ou capacidade de resiliência".

A preocupação vem também direcionando à segunda dimensão, a econômica, com vista para o uso regrado de recursos naturais como água e minerais. O pensamento de recursos infinitos já não existe. Bens como a água, que teoricamente é abundante em nosso planeta, também é fortemente ameaçada pelo uso desenfreado. Para Nascimento (2012, p.55) A segunda dimensão, a econômica, supõe o aumento da eficiência da produção e do consumo com economia crescente de recursos naturais, com destaque para recursos permissivos como as fontes fósseis de energia e os recursos delicados e mal distribuídos, como a água e os minerais".

Do ponto de vista da terceira dimensão, a social, todas as pessoas precisam ter o mínimo de recursos para suprir suas necessidades, desde que não seja prejudicial aos outros, conferindo assim uma justiça social e compartilhamento igualitário dos recursos naturais. Nascimento (2012, p.56) aborda ainda que "Uma sociedade sustentável supõe que todos os cidadãos tenham o mínimo necessário para uma vida digna e que ninguém absorva bens, recursos naturais e energéticos que sejam prejudiciais a outros".

Neste sentido encontra-se muitas práticas voltadas ao cuidado com o meio natural e a preservação de recursos naturais. Uma prática sustentável a que damos destaque é a utilização de fios de fibras naturais na construção de artefatos artesanais e de moda.

\section{Abordagem social da produção com viés sustentável}

Somos indivíduos racionais, capazes de pensar nas necessidades específicas não só particulares, mas, também do coletivo. Essa característica nos molda desde os primórdios de forma que nos tornamos "humanos", desde sempre viemos carregando conosco a genética, que nos faz semelhantes, e a cultura que molda nossos hábitos mais peculiares.

Nós (agentes), levantamos experiências inovadoras para a vida social a qual criamos e moldamos o tempo todo. Com olhar voltado especificamente para a sociedade, Bourdieu traz conceitos que nos ajudam a entender a influência que sofremos. 


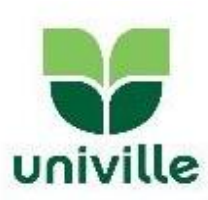

Para se compreender melhor as estruturas sociais a teoria de Bourdieu deixa o entendimento de que a sociedade pode ser compreendida por meio de 3 conceitos chaves: campo, habitus e capital simbólico.

O Campo (estrutura objetiva) segundo Bourdieu (2008; 2011) apud Hermes (2017, p. 53.) "configura-se em um espaço social em que as dinâmicas práticas ocorrem..." esse campo pode ser uma empresa, escola, igreja etc. Nesse sentido, para complementar essa definição, Bourdieu (2008; 2011) apud Hermes (2017, p. 53.) afirma ainda que "O campo possui propriedades particulares, uma lógica social própria estruturada e estruturante, porém não é imutável; sofre influência dos agentes envolvidos e dos conflitos simbólicos inerentes".

O conceito de habitus (estrutura subjetiva), Bourdieu (2011, p. 201) aborda que "O princípio unificador e gerador de todas as práticas... não é outra coisa senão o habitus, sistema de disposições inconscientes que constitui o produto da interiorização das estruturas objetivas (...)", habitus está muito ligado a cultura.

Quanto ao capital simbólico, Bourdieu e Cherques (2011;2006) escrevem que: “também pode ser considerado uma estrutura de reconhecimento social que envolve valores como honra, preponderância, notoriedade." Entende-se que atrelado a esse último conceito está o valor simbólico das "coisas", ligando isso com o produto (para venda) podemos dizer que o valor simbólico de um produto só é percebido por aquele indivíduo que o almeja por uma determinada razão, sentimental ou não, que não é formalmente expresso mas é percebido de forma intrínseca. É essência.

Enquanto sociedade cria-se meios de conciliar as necessidades de um mundo populoso, onde muitas pessoas têm carências das mais diversas formas, com soluções que objetivam ser socialmente corretas e humanas.

A participação social nas discussões é muito importante para o andamento e efetivação dos projetos sustentáveis, o esforço coletivo é necessário para o desenvolvimento e tornam eficaz as ações, nesse sentido, Foladori (2002, p.110) aborda: "Voltando à questão da participação social, trata-se, talvez, da temática mais interessante dentro da discussão sobre sustentabilidade social. A participação é um indicador de liberdades democráticas, de equidade nas decisões, e também um elemento decisivo na potenciação dos esforços produtivos".

Em tempos modernos a participação "social" é mais relevante que outrora, as pessoas já não são apenas ouvintes absorvendo as informações, tomam para si o poder de decisão, de ação e de compartilhamento. Foladori (2002) escreve que o conceito de participação mudou da participação simplesmente informativa para o que hoje se conhece como empoderamento (do Inglês: empowerment) onde os participantes discutem até as diretrizes estratégicas.

Essa maior participação popular, associada ao termo empoderamento (empowerment), é um avanço social no tocante a tomadas de decisões. Conforme Foladori (2002, p.110) “... É claro que hoje em dia, o conceito de participação associado à ideia de empowerment é o que prevalece, pelo menos no discurso. Não pode existir dúvida de que isso significa um avanço civilizatório significativo diante das mais antigas versões.”.

Neste sentido pode-se fazer uma ligação com os crescentes grupos de trabalhos com mulheres, especialmente de baixa renda ou em situação de vulnerabilidade, incentivando maior participação social. Nota-se um engajamento por parte dos profissionais de Design de moda, nas questões sociais, por meio de criações artesanais e projetos de geração de renda. 


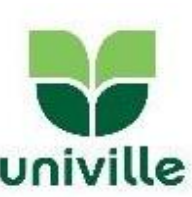

Muitas iniciativas são levantadas no sentido de agregar valor ao produto, esse valor pode por vezes ser palpável, mas em grande parte nota-se um valor simbólico, agregado de forma singela, por meio da expressão cultural, reproduzidas no produto. Esse toque cultural vai desde a escolha dos materiais base, cultivados e tratados de forma artesanal, até o acabamento. Conforme se verifica em Morgenstern e Aguiar (2015, p.34) "A moda apropriase dos mais variados elementos culturais e sociais para criar tendências e lançar novos produtos no mercado. Logo, ela também se apropria de elementos populares, como o artesanato.".

Nota-se que muitas ações vêm sendo executadas, em nível de Brasil, voltados à produção de artefatos sustentáveis, com vistas para a preservação do meio ambiente; crescimento social e econômico justo. As ações vêm desde pequenos artesanatos construídos por artesãos autônomos a cooperativas e empresas com viés sustentável mesclando cultura.

O impacto das iniciativas de produção de artefato ambientalmente amigável, socialmente falando, é uma qualidade de vida que vem sendo reconstruída pouco a pouco, através dos cuidados (nas três dimensões da sustentabilidade) para que a utilização regrada e consciente dos recursos naturais seja o foco do projeto.

Em Santa Catarina, que tem matéria natural abundante, podemos verificar grupos focados no desenvolvimento de produtos tendo a possibilidade de geração de renda através da comercialização dos mesmos. Em Ashby (2011, p. 04), verifica-se que "Combinadas materialidade e eficiência permitem ao designer desenvolver produtos que sejam inovadores e, ainda assim, expressões totalmente tangíveis e otimizada de uma ideia. Essa é a ideia que chegará ao mercado.". Neste sentido a prática se traduz em eficiência e a abundância e características das fibras em materialidade.

\section{Fibras naturais: fibras de paina e fibras de bananeira}

A propagação da ideia e conscientização acerca da busca de materiais naturais para a construção de produtos está crescendo. O campo do design, por meio de seus métodos, tem muito a contribuir com esse novo paradigma. Acredita-se que a falta de reflexão, acerca do habitus vigente, na produção e consumo, relativos a produtos e materiais sustentáveis, pode trazer, em curto prazo, uma dificuldade maior na obtenção de matéria natural. Todos os recursos naturais são finitos e a preocupação com essa escassez é visível.

\subsection{A fibra paina}

A fibra Paina é uma fibra vegetal, vinda da Paineira, que é uma arvore nativa Brasileira. Tem características muito parecidas com às do algodão, branca, muito leve e suave. Essas características despertam a curiosidade e a intenção de estuda-la e avaliá-la como alternativa de matéria prima para uso têxtil. Conforme Lorenzi (2000): o nome científico da Paineira é Chorisia Speciosa; e um de seu nome popular é Paineira. 


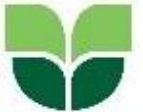 \\ univille}

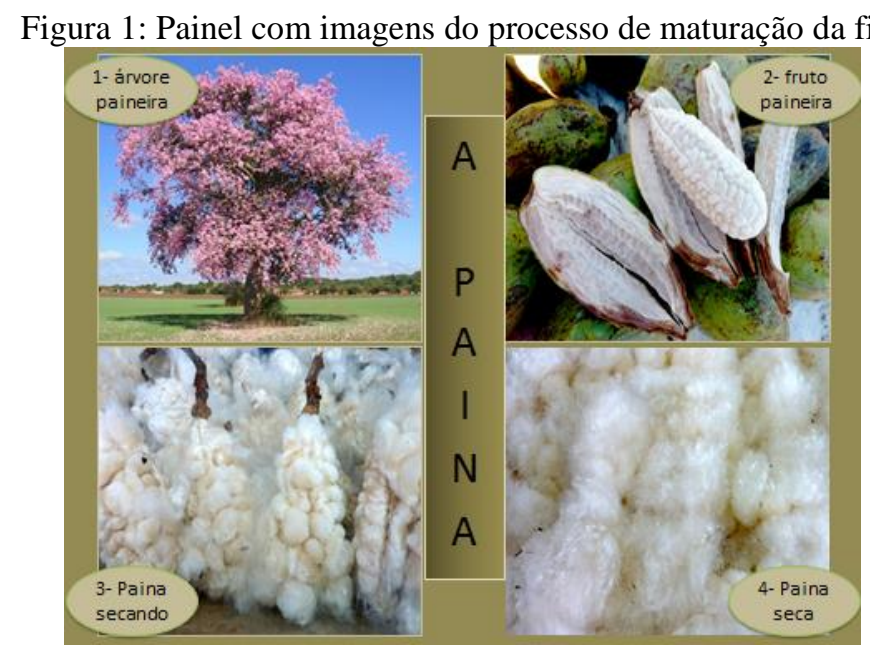

Fonte: www.deverdecasa.com (2017)

Na primeira fase dessa pesquisa, com vistas à aplicabilidade da fibra vegetal Paina, foi desenvolvido um fio mesclado com a fibra natural animal Lã de Carneiro. O processo de construção do fio por meio artesanal foi registrado por imagens, o quadro a seguir mostra o passo a passo desde a avaliação da fibra até o fio pronto. $\mathrm{O}$ desenvolvimento foi totalmente por processos artesanais, conduzidos pela artesã Nara Guichon.

Figura 5: Painel de construção do fio ( $1^{\mathrm{a}}$ fase da pesquisa)

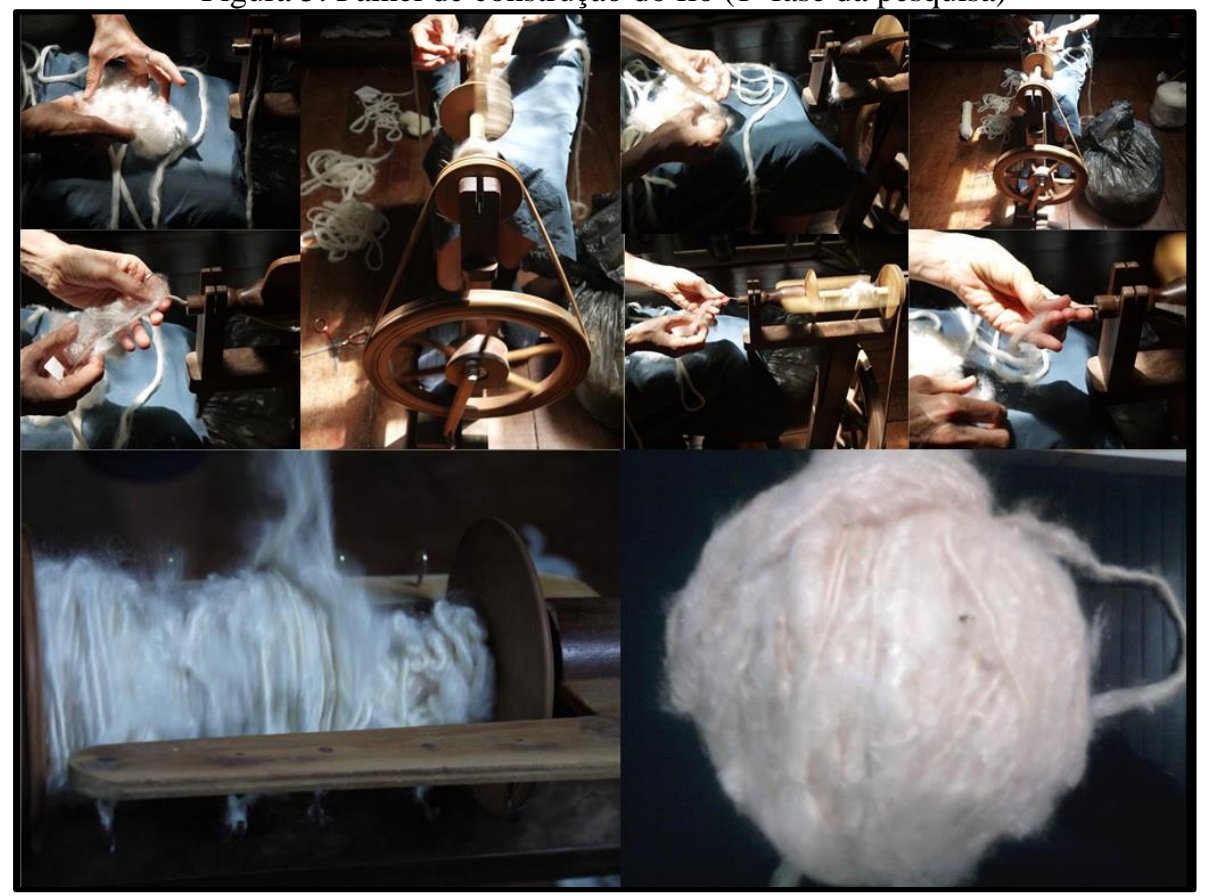

Fonte: Autora

A escolha de utilização de meios artesanais foi proposital. Dessa forma facilitou-se a observação do comportamento da fibra em relação ao manuseio; mescla; e até as implicações, 2017, UNIVILLE, Joinville, SC 


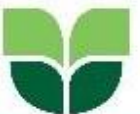 \\ univille}

que as características da fibra provocam, quanto à textura, espessura e comprimento, relacionados à fiação. A utilização de mão de obra Catarinense foi vista como uma tentativa de agregar conhecimento cultural e local ao projeto.

\subsection{A fibra da bananeira}

A fibra do pseudocaule da bananeira é de constituição vegetal, provinda da bananeira, que é planta abundante em Santa Catarina, principalmente nas regiões ao leste e noroeste do estado. A fibra de bananeira, tem característica alongada e firme, dessa forma sugere ser uma boa opção para ser trabalhada como "miolo de fio". Assim como a fibra Paina essas características despertam a curiosidade e a intenção de estudá-la e avaliá-la, como alternativa de matéria prima para uso têxtil. A produção de bananeira é muito presente em Santa Catarina. Gonçalvez Filho (2011) descreve as porcentagens de produção de bananeira de acordo com cada microrregião geográfica, com destaque para Joinville (55\%) do volume total, seguida por Blumenau $(19,1 \%)$ e Itajaí que do total estadual foi responsável por $15,4 \%$ da produção do estado. Juntas somam 89,5\% da produção no ano 2008 que foi de 624,2 mil toneladas.

A boa produção de banana, por consequência, é capaz de fornecer material natural de fibra em grande volume, já que a extração da fibra de bananeira é retirada do pseudocaule da planta. O pseudocaule é um dos resíduos gerados a partir da colheita da banana, Gonçalves Filho (2011) aponta que, para cada tonelada de banana colhida, são gerados resíduos, entre eles 3 toneladas de pseudocaule.

Figura 2: Desenho esquemático da Bananeira.

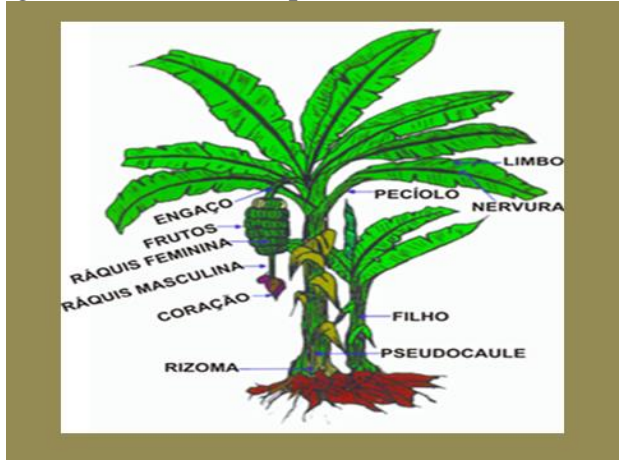

Fonte: Embrapa (2017)
Figura 3: Fibra da bananeira depois de processada

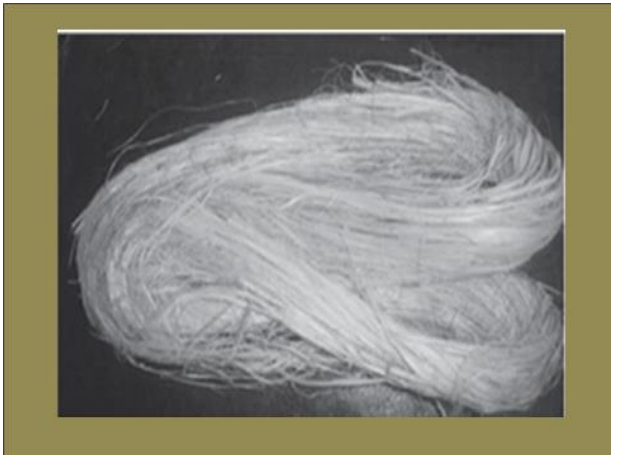

Fonte: www.scielo.br (2017)

A fibra da bananeira vem sendo pesquisada para utilizada para construção de têxteis, além disso, todas as características da fibra e o contexto geral, de cultura local e cultivo da planta, são favoráveis à continuação de pesquisas em desenvolvimento de produto manufaturado e artesanal.

As fibras de bananeiras são muito utilizadas na confecção de utensílios domésticos (cestos), acessórios de moda (colares, bolsas, pulseiras etc). Existem muitas possibilidades de utilização da fibra entre elas, destaca-se, a utilização na confecção de papel reciclado. Como trabalho de conclusão de curso de Mestrado Débora Baraúna, em 2009, apresentou com êxito o trabalho intitulado "Sistema de gestão ambiental (sga): uma aplicação na produção de Papel 


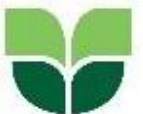 \\ univille}

reciclado artesanal com adição de diferentes frações Mássicas de fibras de bananeira" que tratou da fabricação de papel reciclado misturando a fibra de bananeira.

Essas iniciativas direcionam seus trabalhos no intuito de preservar o meio ambiente, diminuindo a destinação de resíduos de bananeira (caule) ao solo. Visto que é danoso ao meio ambiente.

Em visita a campo, observou-se o caminho percorrido pra processar a fibra do pseudocaule da bananeira desde a preparação do caule até o uso das fibras na construção de artefato (quadro). A figura 4 ilustra o trajeto sendo: Retirada, limpeza do caule e separação das folhas, para posteriormente passar no cilindro; Passada no cilindro, para facilitar a retira a da fibra, nesse processo de passada no cilindro, a fibra renda danifica-se. Caso ela precise ser retirada, para alguma aplicação, o processo de amaciar deve ser feito manualmente; Mergulho no tanque com água limpa e água sanitária, para limpar as impurezas grudadas nas folhas; Tiragem das camadas de fibras: neste passo são separadas as camadas de fibras para posterior utilização. Consegue-se a retirada de três camadas a fibra: mole, fibra dura e a renda; Separação das fibras e secagem das fibras: após a retirada das camadas de fibras, separam-se aquelas que serão utilizadas. Elas são encaminhas para uma estufa ou, se for um dia ensolarado e seco, pode-se secar ao sol; Seleção das fibras: depois de secas as fibras são selecionadas de acordo com a sua utilidade ou trabalho a ser feito; Preparação das fibras: neste passo as fibras são preparadas para a utilização; Aplicação: Depois de preparadas, as fibras serão aplicadas nos artefatos de acordo com a solicitação do cliente ou do projeto desenvolvido.

Figura 4: trajeto percorrido para a preparação e utilização da fibra.

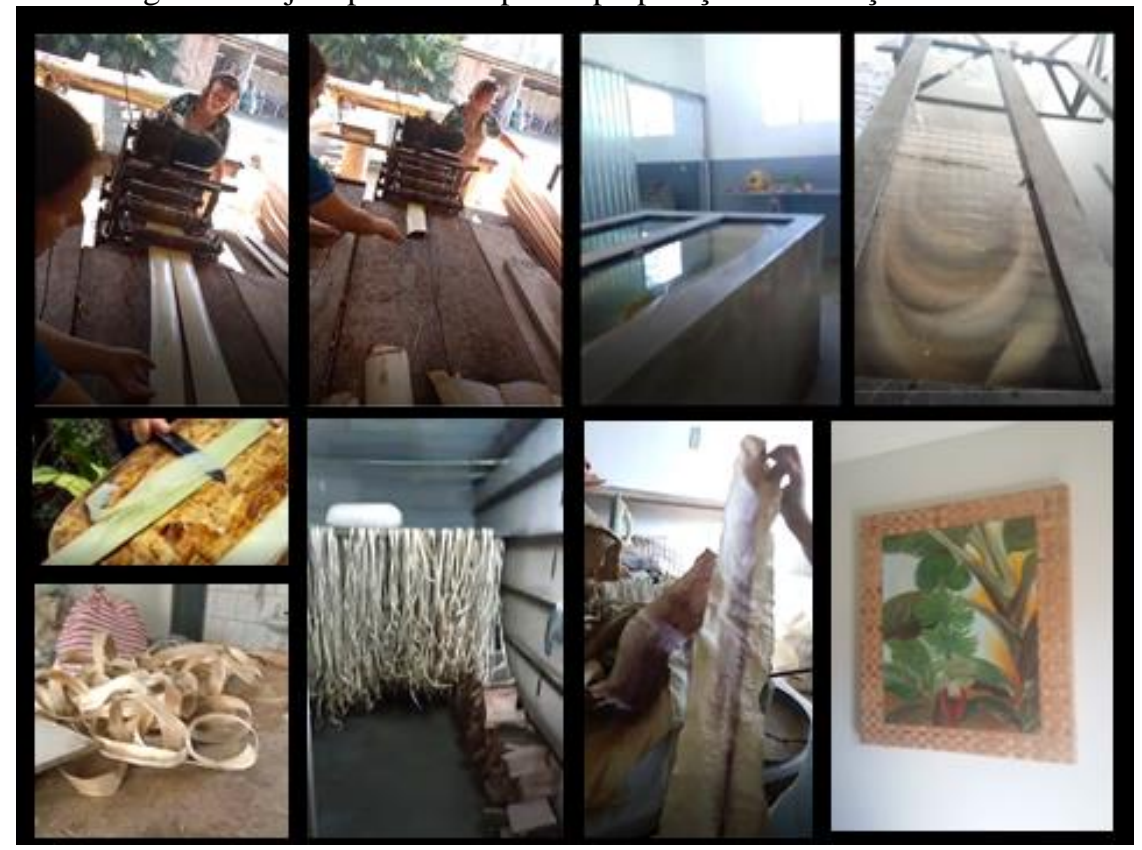

Fonte: arquivo pessoal

Para que o artefato adquira durabilidade e resistência, é preciso preparar a fibra de bananeira de forma correta e cuidadosa. 


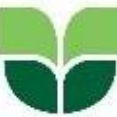 \\ univille}

\section{Consumidor movido por valores e mercado}

O consumidor está cada vez mais atento e exigente quanto a questões ambientais, esse comportamento inspira a busca por alternativas sustentáveis em matéria prima, buscando a cooperação entre individuo, social e natureza. Vezzoli apud Schulte e Lopes, (2008, p.34) discorre nesse aspecto “... a preocupação com a preservação do meio ambiente, no processo de desenvolvimento de produtos, passa a fazer parte do sistema da moda. Já é possível encontrar no mercado brasileiro algumas marcas que trabalham com este valor agregado a seus produtos e este número está crescendo".

Percebe-se um tipo de Consumo Consciente. Atitudes conscienciosas se levantam cada vez mais, seja na aquisição de produtos ambientalmente amigáveis, de bens "simbólicos" ou mesmo de produto com valor simbólico agregado. Aburdene (2011, p.107) descreve o Consumidor Consciencioso ou Consumidor movido por valores: “... se os valores, mais do que seu ganho, sua demografia, onde você reside ou qualquer outro fator influencia profundamente como você "vota na caixa registradora", seja por ter comprado um café a preço justo, camisas de algodão orgânico ou aquele novo Honda híbrido, você é um Consumidor Consciencioso".

Caminhamos para o crescimento atitudes humanitárias e socialmente corretas, guiados por valores. Essas atitudes emergem em meio à situação caótica de consumo. Aburdene (2011, p.107) escreve que: "Essa tendência é o nascimento do Consumidor Movido por Valores ou do Consumidor Consciencioso, que se estima já sejam 63 milhões de pessoas (nos estados Unidos) e que estão transformando o capitalismo".

Atitudes estão se levantando para atender às necessidades do consumidor que preza por um conjunto de valores (social, cultural, econômico, ambiental). Aburdene (2011, p.108) descreve que "Os consumidores Conscienciosos também são atraídos por produtos que contêm ou transmitem valores". Nesta linha de pensamento verifica-se, ainda, em Aburdene (2006, p. 109) que “... A maioria dos consumidores conscienciosos leva uma vida confortável; alguns possuem receita excedente, mas todos desdenham do consumismo e nada querem ter a ver com o mercado das massas, seja ele de descontos ou da moda, ou, ainda, qualquer coisa deste meio".

Nota-se, portanto, que esses consumidores conscientes podem configurar-se em um nicho de mercado, uma fatia de mercado a ser atendido, se pensarmos que a maioria dos produtos encontrados não possui viés ambientalmente amigável. Destaca-se que o consumo consciente é na verdade uma necessidade para a manutenção do planeta. Mas esse cenário precisa ser avaliado.

Para uma possível avaliação de cenário Aaker (2001, p. 117) aponta passos estratégicos para analisar cenários: 
Figura 5: passos para análise de cenários.

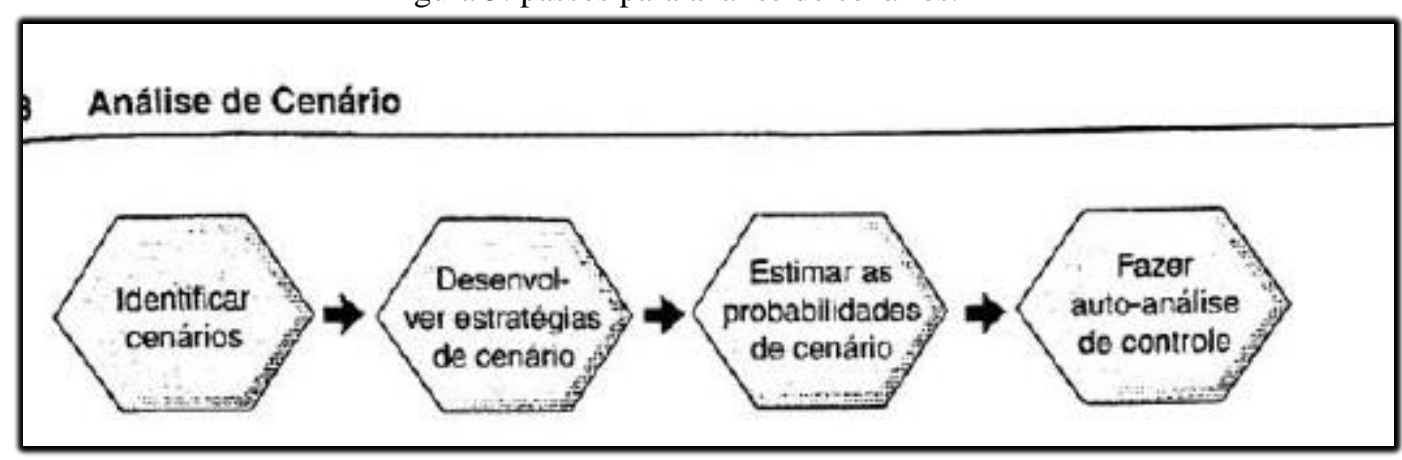

Fonte: Aaker (2001)

A possibilidade de obter-se renda por meio do comércio de produtos gerados a partir do trabalho com fibras naturais é ampla. Através disso pode-se diminuir a agressão ao meio ambiente; apreciar e valorizar culturas, por intermédio de ações voltadas à produção e comercialização de produtos produzidos artesanalmente.

\section{Produtos artesanais sustentáveis e a valorização internacional}

Numa retrospectiva de dados obtém-se que, 2003 eram exportados o equivalente a US\$ 10 mil em produtos artesanais. Vieira (2013, p.01) aponta que "Dos modestos US\$ 10 mil apurados em 2003, quando os artesãos estavam ainda engatinhando num mercado novo, eles alcançaram a cifra de US\$ 20 milhões em 2012. As informações em 2013 ainda conforme Vieira (2013, p. 01) dava conta de que as exportações 2012 "foi turbinado pela demanda de grandes redes varejistas que passaram a valorizar o artesanato brasileiro, a exemplo do magazine norte-americano Macy's, das gigantes TJMaxx, dona das marcas Home Goods, Home Sense e Winners, e da espanhola El Corte Inglés.”

Tabela 01: Ranking de países importadores de artesanato

\begin{tabular}{|l|c|}
\hline $\begin{array}{l}\text { O ranking dos } 12 \text { países que mais compraram o artesanato brasileiro em } 2013 \\
\text { DESTAQUES }\end{array}$ \\
\hline França & $29,2 \%$ \\
\hline Reino Unido & $26 \%$, \\
\hline Estados Unidos & $22 \%$ \\
\hline Alemanha & $5,5 \%$. \\
\hline \multicolumn{2}{|c|}{ Fonte: Autora }
\end{tabular}

Em 2016 a parceria firmada entre Sebrae e Apex Brasil (Agencia Brasileira de Promoções e Investimentos) continua abrindo portas para a exportação de peças artesanais brasileiras. Um milhão de dólares em encomendas que devem ser entregues dentro dos 12 


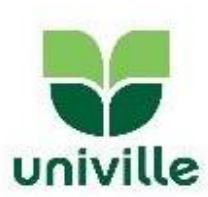

meses de 2017. Em Sebrae (2017) lê-se que neste ano de 2017 o artesanato brasileiro estará em lojas no exterior. Em Novembro de 2016, 31 artesãos venderam mais de U\$27 mil para donos lojas de museus, galerias de artes, loja de departamentos, pequenos centros comerciais e boutiques. Foram encomendados mais de um milhão de dólares em peças, pelos compradores estrangeiros.

Destaca-se ainda exposição feita por empresa Catarinense. A 'Das Catarinas Brasil, expôs em Londres (2016) na Inglaterra e fez exportações, através da parceria Sebrae-Apex.

O Sebrae ainda indicou empresas de artesanato brasileiro para expor na Maison \& Objet, feira de arte e decoração em Paris. Em Sebrae (2017) lê-se ainda que “...O artesão quer exportar, mas não tem nota fiscal, embalagem adequada, site - e quando tem não está em inglês -, não sabe calcular um preço de venda de exportação. Vamos ajudar a derrubar essas barreiras".

Outro exemplo de empresa de produtos artesanais Catarinense, que vem exportando seus produtos artesanais é a Nangara. A empresa é de Joinville, trabalha com biojóias e utiliza de material mais próximo possível do natural. O aproveitamento de materiais residuais de empresas também faz parte das atitudes da empresa. Esse empreendimento familiar em produtos artesanais já vende para o exterior, no momento a exportação é focada no cliente final e atendem nos Estados Unidos, Canadá, Reino Unido, França, Alemanha, Austrália e Argentina.

\section{Conclusão}

A temática destacada no artigo alerta para a importância de tratar as questões ambientais como primordiais. A sociedade como um todo pode beneficiar-se com atitudes sustentáveis, portanto, algumas dessas iniciativas foram destacadas.

Os impactos sociais abordados ilustraram a oportunidade de desenvolvimento local nos aspectos economico e social por meio de trabalho e renda, a partir das vendas dos artefatos artesanais. Tratou-se ainda do avanço social nas tomadas de decisões e na maior participação (empoderamento) das pessoas envolvidas, enquanto agentes transformadores da realidade social estabelecida.

Estimando-se que a mudança de hábito ocorrerá a partir da conscientização, incetivouse a prática com viés sustentável por meio de exemplos de sucesso. Com a crescente expectativa de preservação dos recursos naturais, os materiais destacados na pesquisa foram: as fibras de bananeira e da paineira, com vistas à produção de material têxtil sustentável, por meio do uso de recursos naturais que são renováveis, para posterior aplicação em artefatos artesanais.

A utilização da fibra de bananeira é destacada por meio da sua frequente utilização na construção de artefatos artesanais. Notadamente é um material com muitas possibilidades de uso, assim como a Fibra de Paineira, já utilizada em testes de fabricação de fios têxteis artesanais entre outros artefatos.

Durante o desenvolvimento deste artigo a pesquisa fundamentou a importância ao tratar da construção de artefatos de viés sustentável com a utilização de fibras naturais, e abordou alguns aspectos sobre caracetrísticas das fibras de paina e de bananeira. Esse artigo tem olhar voltado ao comportamento e estilo de vida sustentável, que deriva da macrotendência do consumo consciente. Foi proposta uma reflexão acerca do consumidor movido por valores e a 
influencia no mercado, constata-se que esse novo "tipo" de consumidor está trasnformando-se em um nicho de mercado interessante, observados enquanto "influenciadores" no consumo de forma positiva, pois, como já mencionado o consumo consciente é uma necessidade para a manutenção do planeta e não para aumentar vendas de produtos.

Por fim, conclui-se que existe possibilidade de inserção dos artefatos artesanais com viés sustentável no mercado internacional e destaca-se, entre os exemplos, a parceria entre Sebrac e APEX. Os meios de inserção aqui abordados são alguns dentro de outros possíveis. A partir disso abre-se oportunidades para a continuação de pesquisa envolvendo outros meios de inserção dos produtos no mercado.

\section{Referências}

AAKER, David A. Administração estratégica de Mercado. Porto Alegre: Bookman, 2001

ABURDENE, Patrícia. Megatrends 2010: o poder do capitalismo responsável. Rio de Janeiro: Elsevier, 2006.

APEX. Disponível em <http://www.apexbrasil.com.br/home/index $>$ acesso em: 26 de Maio de 2017 às $15 \mathrm{~h} 12 \mathrm{~min}$.

ASHBY, M.F. Materiais e Design: arte e ciência da seleção de materiais no design de produto/Michael Ashby e Kara Jhonson; tradução de Arlete Simille Marques; revisão técnica de Mara Martha Roberto e Ágata Tinoco. - Rio de Janeiro: Elsevier, 2011.

BOURDIEU, Pierre; A Economia das Trocas Simbólicas.- $8^{\text {a }}$. ed.- São Paulo: Perspectiva, 2015. $361 \mathrm{p}$.

CARDOSO, Juliana. O design como ferramenta para a sustentabilidade: estudo de caso do couro de peixe. Universidade Federal de Uberlândia - UFU; Faculdade de Arquitetura, Urbanismo e Design, 2008.

Fibra de Bananeira. Disponível em: <http://www.scielo.br/scielo.php?script=sci_arttext\&pid=S0104-14282007000100004>. Acesso em 15 de Março de 2017 às $12 \mathrm{~h} 45 \mathrm{~min}$.

FOLADORI, Guillermo. Avanços e limites da sustentabilidade social. R. paran. Desenv. Curitiba, n. 102, p. 103-113, jan./jun. 2002

GONÇALVES FILHO, Luiz Carlos. Utilização do pseudocaule de bananeira como substrato da fermentação alcoólica: avaliação de diferentes processos de despolimerização/ Luiz Carlos Gonçalves Filho; Orientador Dr. Ozair Souza - Joinville: UNIVILLE, 2001. 


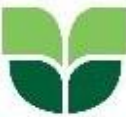 \\ univille}

GUICHON, Nara. Nara Guichon Têxtil. Disponível em http://www.naraguichon.com/perfil.php?menu=perfil. Acesso em: 19:35hs 12/11/2012.

HERMES, Leticia. Design e Projetos Sociais: Processos e efeitos da extensão universitária. 2017. 134f. Relatório (Mestrado em Design) - Universidade Comunitária da Região de Joinville, Joinville, 2017.

LORENZI, Harri. Árvores Brasileiras: manual de identificação e cultivo de plantas arbóreas nativas do Brasil. $3^{\mathrm{a}}$ ed., Nova Odessa,SP:Instituto Plantarum,2000. São Paulo: Editora Nova Fronteira, s.a.

MANZINI, Ezio. Design para a inovação social e sustentabilidade: comunidades criativas, organizações colaborativas e novas redes projetuais. Rio de Janeiro: E-papers, 2008. 104p.

NAIME, Roberto; ASHTON, Elisa; HUPFFER, Haide Maria. Do design ao ecodesign: pequena história, conceitos e princípios. Rev. Elet. em Gestão, Educação e Tecnologia Ambiental (e-ISSN: 2236-1170) NAIME et al., v(7), nº 7, p. 1510-1519, MAR-AGO, 2012.

NANGARA. Biojóias. Disponível em: 'http://www.nangara.com.br/a-marca-pg-18f2d acesso em: 28 de Maio de 2017 às 16h14min.

NASCIMENTO, Elimar Pinheiro do. Trajetória da sustentabilidade: do ambiental ao social, do social ao econômico. Estudos avançados 26 (74), 2012.

DEVERDECASA. Paina. Disponível em: < http://www.deverdecasa.com/2012/08/painapara-dar-e-vender.html. > Acesso em: 22 de Fevereiro de 2017 às 17h24min.

PLANTA BANANEIRA. Disponível em: http://www.agencia.cnptia.embrapa.br/Agencia40/AG01/arvore/AG01_31_41020068055.htm 1 > Acesso em: 20 de Março de 2017 as 14h03min.

SCHULTE, Neide Köhler; LOPES, Luciana. Sustentabilidade ambiental: um desafio para a moda. Modapalavra e-periódico. Ano 1, n.2, ago-dez 2008, pp. 30 - 42. ISSN 1982-615x

SEBRAE. Made in brazil ganha impulso com artesanato. Disponível em $<$ http://www.agenciasebrae.com.br/sites/asn/uf/NA/made-in-brazil-ganha-impulso-comartesanato,bb01388ff4469510VgnVCM1000004c00210aRCRD> Acesso em: 27-05-2017 às $21 \mathrm{~h} 57 \mathrm{~min}$. 